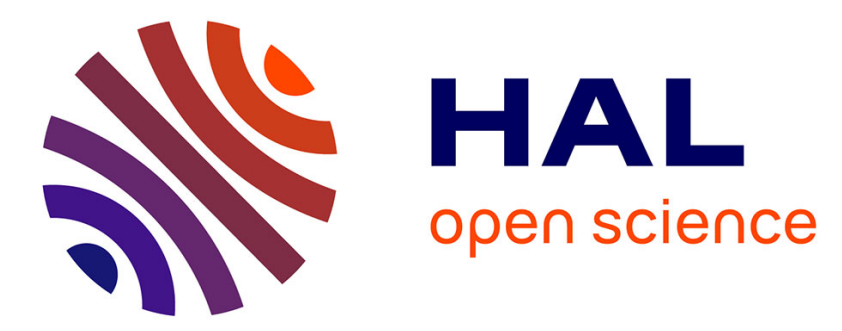

\title{
Structural seismic fragility analysis of RC frame with a new family of Rayleigh damping models
}

\author{
Pierre Jehel, Pierre Léger, Adnan Ibrahimbegovic
}

\section{To cite this version:}

Pierre Jehel, Pierre Léger, Adnan Ibrahimbegovic. Structural seismic fragility analysis of RC frame with a new family of Rayleigh damping models. Manolis Papadrakakis, George Stefanou, Vissarion Papadopoulos. Computational Methods in Stochastic Dynamics - Vol. 2, 26, Springer, pp.267-291, 2013, Computational Methods in Applied Sciences, 978-94-007-5134-7. 10.1007/978-94-007-5134-7 . hal-00730603

\section{HAL Id: hal-00730603 \\ https://hal-centralesupelec.archives-ouvertes.fr/hal-00730603}

Submitted on 2 Aug 2018

HAL is a multi-disciplinary open access archive for the deposit and dissemination of scientific research documents, whether they are published or not. The documents may come from teaching and research institutions in France or abroad, or from public or private research centers.
L'archive ouverte pluridisciplinaire HAL, est destinée au dépôt et à la diffusion de documents scientifiques de niveau recherche, publiés ou non, émanant des établissements d'enseignement et de recherche français ou étrangers, des laboratoires publics ou privés. 


\title{
Structural seismic fragility analysis of RC frame with a new family of Rayleigh damping models
}

\author{
Pierre Jehel ${ }^{1}$, Pierre Léger ${ }^{2}$, Adnan Ibrahimbegovic ${ }^{3}$
}

August 14, 2012

${ }^{1}$ MSSMat (École Centrale Paris/CNRS),

Grande Voie des Vignes, 92295 Châtenay-Malabry Cedex, France

pierre.jehel [at] ecp.fr

${ }^{2}$ École Polytechnique of Montreal, Department of Civil Engineering,

University of Montreal Campus, P.O. Box 6079, Station CV Montreal, QC, Canada H3C 3A7

pierre.leger [at] polymtl.ca

${ }^{3}$ LMT-Cachan (ENS Cachan/CNRS/UPMC/PRES UniverSud Paris),

61 avenue du Prsident Wilson, 94235 Cachan Cedex, France

ai [at] lmt.ens-cachan.fr

\begin{abstract}
Structural seismic vulnerability assessment is one of the key steps in a seismic risk management process. Structural vulnerability can be assessed using the concept of fragility. Structural fragility is the probability for a structure to sustain a given damage level for a given input ground motion intensity, which is represented by so-called fragility curves or surfaces. In this work, we consider a moment-resisting reinforced concrete frame structure in the area of the Cascadia subduction zone, that is in the South-West of Canada and the North-West of the USA. According to shaking table tests, we first validate the capability of an inelastic fiber beam/column element, using a recently developed concrete constitutive law, for representing the seismic behavior of the tested frame coupled to either a commonly used Rayleigh damping model or a proposed new model. Then, for each of these two damping models, we proceed to a structural fragility analysis and investigate the amount of uncertainty to be induced by damping models.
\end{abstract}

Keywords: Damping; Inelastic time-history analysis; Structural fragility; Fiber beam element; Reinforced concrete frame structure; Earthquake. 


\section{Introduction}

Decision makers are interested in seismic risk analyses for predicting the postearthquake situation in a given geographical region, so as to anticipate the human, social and economical impact of a major earthquake. For building structures, seismic risk assessment requires three main steps. i) A seismic hazard analysis has first to be performed. It can be either deterministic or probabilistic. In the latter case, the seismic hazard is often expressed as an intensity measure - often the peak ground acceleration $(P G A)$ - with a certain probability of being exceeded in a certain number of years. ii) Then, the seismic fragility of the building considered has to be estimated: it corresponds to the conditional probability $P_{i j}=P[D I \geq$ $D I_{i} \mid I M=I M_{j}$ ] of the building to sustain a given damage index $D I_{i}$ for a unique - or a set of - given input ground motion intensity measures $I M_{j}$. The probability to attain a damage index $D I_{i}$ can then be computed as

$$
P_{i}=\sum_{j} P\left[D I \geq D I_{i} \mid I M=I M_{j}\right] \cdot P\left[I M=I M_{j}\right] .
$$

These damage indices have to be related to building performance requirements. iii) Finally, the exposure of the buildings and populations has to be determined.

Structural seismic fragility analysis thus is a key step in the overall earthquake risk management process. This task is commonly achieved by constructing fragility curves from inelastic time-history analyses that take into account the variability in the seismic input motion alone or in both the input motion and the structural model. The main ingredients for fragility analyses are: i) A set of seismic timehistory records representative of the seismic hazard in the geographical region of interest for the project; ii) An inelastic structural model along with a damping model; iii) A mapping between damage indices and structural performance levels; and iv) Statistical tools to analyze fragility curves.

In [1], Hwang and Huo present a methodology for constructing fragility curves accounting for uncertainties in the seismic, site, and structural parameters. On the one hand, 8 scenario earthquakes corresponding to different $P G A$, annual exceedance probabilities, magnitudes, and source-to-site distances are considered; for each scenario, 50 samples of ground motion time histories are generated using a seismological model that takes into account uncertainties in seismic and soils parameters. On the other hand, 50 samples of each of 6 random structural parameters are generated and then combined using the Latin Hypercube sampling technique to eventually generate 50 samples of the inelastic structural model. Then, for each earthquake scenario, the 50 ground motion samples are combined with the 50 structural samples to establish 50 earthquake-site-structure samples. Finally, 
for each earthquake scenario, 50 values of the damage index are computed from inelastic analyses and fragility curves are constructed.

The preceding approach defines a fully probabilistic approach in the sense that it takes into account uncertainty sources in both the seismic input motions and the inelastic structural behavior. It can however also be worth considering only uncertainties in ground motions. To that purpose, there exists, following Jalayer and Beck [2], an alternative to the IM-based approach considered in this work: the probabilistic ground motion time history approach. This latter method is based on a stochastic ground motion model pertaining to seismic source parameters, which has to circumvent the most difficult drawback to be tackled in the $I M$-based approach, namely whether the selected set of $I M$ thoroughly represent the input signal characteristics. On another hand, the recent work of Rosić et al. [3] considers the uncertain structural response of inelastic media and deterministic loading to provide maps of the probability for a component of the stress tensor to reach a given value at a given point.

The concept of fragility curve reduces the vulnerability analysis to the consideration of a unique intensity measure. This limitation has been pointed out in research work where the concept of fragility surfaces emerged. In a study dedicated to the analyze of the limitations of commonly used intensity measures for fragility analysis of single-degree-of-freedom linear and nonlinear systems [4], Kafali and Grigoriu propose to construct fragility surfaces instead of curves for assessing the seismic performance of nonlinear systems. For a given state of damage in the structure, the proposed fragility surface is the graphical representation of the relationship between the failure probability and the set of intensity parameters $(m, r)$ constituted of the moment magnitude $m$ and source-to-site distance $r$. This concept of fragility surface is also used in [5] by Seyedi et al. who extend it to other intensity measures. Indeed, they construct fragility surfaces that provide the probability for an inelastic reinforced concrete structure to sustain a given inter-story drift ratio, according to the spectral displacement at both eigenperiod $T_{1}$ and $T_{2}$. They finally conclude that when dealing with uncertainties propagation, fragility surfaces allow for estimating the variability of structural fragility due to a second $I M$, which should lead to more accurate seismic risk analyses.

Fragility curves have been used as a baseline to deal with a wide range of issues pertaining to earthquake engineering. In [6], Sáez et al. study the effect of considering inelastic dynamic soil-structure interaction on the seismic vulnerability analysis. They construct fragility curves from a very large number of artificially generated input earthquakes. They also introduce the so-called Fisher informa- 
tion concept which allows for measuring the amount of information contained in the seismic ground motions and thus provide a tool for the statistical analysis of fragility curves. In [7], Saxena et al. address the issue of assuming identical support ground motion in the analysis of the seismic response of long, multi-span, reinforced concrete bridges. Analyzing fragility curves, they show that considering spatial variation of earthquake ground motions is of first importance. In [8], Popescu et al. construct fragility curves to present the results of deterministic and both 2D and 3D stochastic analyses of the seismic liquefaction potential of saturated soil deposits. In the context of design rules assessments, Lagaros [9] computes fragility curves to analyze the seismic performance of multi-story RC buildings designed according to Greek and European building codes. The fragility curves are plotted from 10,000 simulations based on Monte Carlo techniques to take into account both uncertainty in the seismic signal and in key structural parameters for assessing structural stability.

There is a likely source of uncertainty in inelastic seismic time history analyses which is only rarely considered in fragility analyses, namely damping added to the inelastic structural model so as to introduce in the simulations an amount of energy dissipation coming from inelastic mechanisms that are not explicitly accounted for in the structural model. In [1], the critical viscous damping ratio added for the seismic analyses of a reinforced concrete frame building is described by the uniform distribution restricted to the range $2 \%-4 \%$. In [10], the structural damping is described by a lognormal distribution with a mean of $2 \%$ and a coefficient of variation of 0.62 for the purpose of steel frame fragility analysis. In both these works, Rayleigh damping is added and the uncertainty pertaining to additional damping thus stems from the critical damping ratio, not from the damping model type - Rayleigh in this case. Because it has been shown that it can be difficult to control the amount of damping generated by common Rayleigh damping models throughout inelastic time history analyses $[11,12,13]$, the main purpose of the work presented in this chapter is to investigate the likely amount of uncertainty introduced by the damping model, in the context of fragility analysis.

To that aim, we proceed as follows. In the next section, we first present a reinforced concrete moment-resisting frame structure - simply referred to as "RC frame" throughout this chapter - which was tested on a shaking table. We use the corresponding experimental data as a reference to validate the developments that we present all along this chapter. Then, we detail in section 3 the numerical model that we use to perform inelastic seismic time-history analyses of the RC frame. The issue of modeling damping is discussed and a new family of Rayleigh damping models is proposed. Results from simulations performed with both a 
"classical" Rayleigh damping model and the proposed new damping model are compared to the shaking table test results so as to validate the capability of the proposed combination of hysteretic with additional damping models for representing the behavior of the RC frame. The proposed new family of Rayleigh damping models can rely on a physical background which often lacks to commonly used Rayleigh damping models. In section 4, we proceed to the selection of a set of real seismic ground motion records compatible with the seismic hazard in the Cascadia subduction zone. A seismic fragility analysis of the RC frame in this geographical region is then carried out in section 5: fragility curves, along with their statistical analysis, as detailed in [6], are constructed for every damping models considered so as to investigate the amount of uncertainty these latter could bring in structural fragility analyses.

\section{RC frame tested on a shaking table}

The test structure considered throughout this chapter is represented in Fig. 1. It was designed at a reduced scale of $1 / 2$ according to the provisions of the National Building Code of Canada [14] and of the Canadian concrete standard [15]. The structure was assumed to have a nominal ductility, which corresponds to a force reduction factor $R=2$ to compute the design base shear. The various assumptions and parameters used in the design of the this structure can be found in [16]. Four inverted U-shape concrete blocks attached in each span of the beams were used to simulate concentrated gravity loads from framing joints. The centers of gravity of the added masses were computed such that they coincide with the center of gravity of the beams. Service cracks were induced by these added masses. The total weight of the frame was $95 \mathrm{kN}$. The fundamental period $T_{1}$ of the structure with added masses was measured at $0.36 \mathrm{~s}$ in a free-vibration test. Mode 1 excites $91 \%$ of the total mass of the structure and when mode 2 is also considered approximately all the mass is excited.

The structure was assumed to be located in a seismic zone 4 in Canada, as depicted in the 1985 seismic zoning map of the National Building Code of Canada. The seismic hazard in this zone is such that peak horizontal ground acceleration between $0.16 \mathrm{~g}$ and $0.23 \mathrm{~g}$ is likely to be observed with $10 \%$ probability of exceedance in 50 years. Such seismic zones can be found in Western, Eastern and Northern Canada. The ground motion record that was selected for the test program corresponds to the N04W component of the accelerogram recorded in Olympia, Washington on April 13, 1949. Fig. 2 presents the feedback record measured during the test initially scaled to a peak ground acceleration $P G A=0.21 \mathrm{~g}$ as well as the corresponding elastic response spectrum with $5 \%$ viscous damping ratio. 

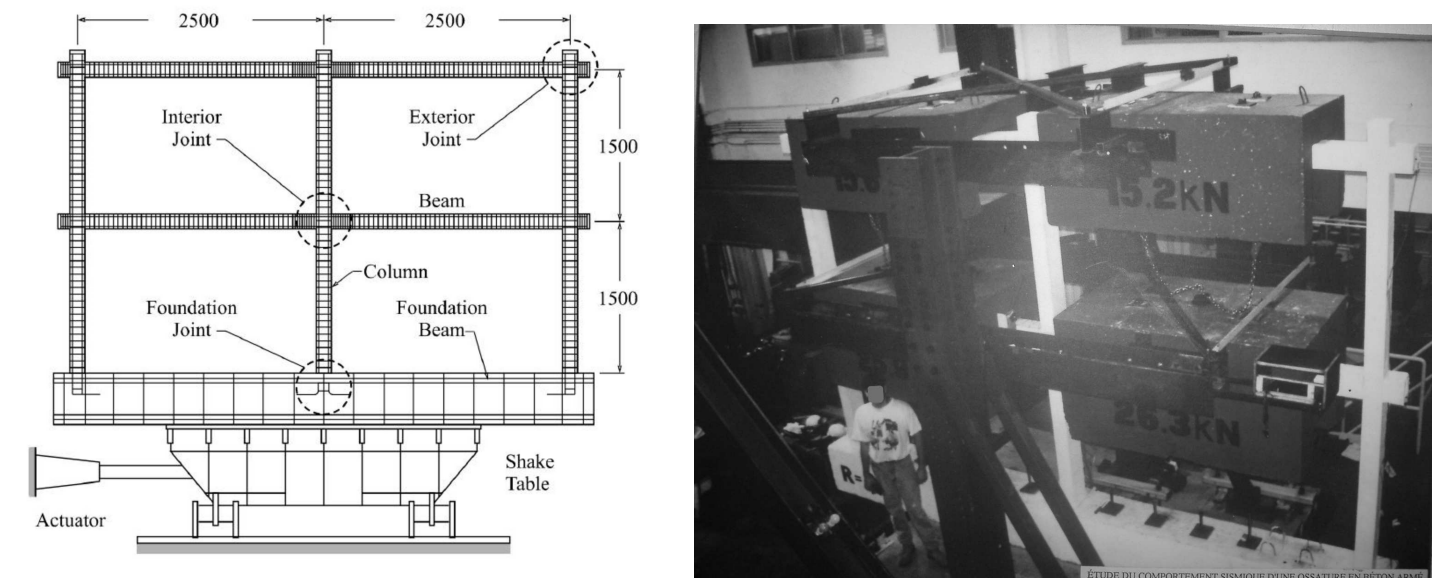

Figure 1: RC frame structure tested on the shaking table at École Polytechnique in Montreal. Dimensions are in [mm].

\section{Seismic inelastic time history analysis of the RC frame}

The set of equations of motion for the discretized structure is written as:

$$
\mathbf{M} \ddot{\mathbf{d}}(t)+\mathbf{C}(t) \dot{\mathbf{d}}(t)+\mathbf{F}_{R}(t)=-\mathbf{M} \Delta \ddot{u}_{g}(t)
$$

where $\mathbf{d}(t)$ is the vector containing the nodal displacements, $\mathbf{M}$ is the mass matrix, $\mathbf{C}(t)$ is the damping matrix, $\mathbf{F}_{R}(t)$ is the inelastic resisting forces vector, $\Delta \ddot{u}_{g}(t)$ is the vector of the rigid body acceleration induced by the ground displacement $u_{g}(t)$. In this section, we first present the inelastic structural model used to compute $\mathbf{F}_{R}(t)$, then we define two damping models: a "classical" Rayleigh model $\mathbf{C}_{1}(t)$ and a new model $\mathbf{C}_{2}(t)$, and we finally validate the capability of the two models for representing the behavior of the $\mathrm{RC}$ frame presented in the previous section.

\subsection{Fiber beam/column element}

The inelastic structural model is based on a fiber frame element suitably implemented in the framework of a displacement-based formulation so that it can integrate the uniaxial concrete behavior law recently developed by the authors [17] and briefly presented in this section. This constitutive model is capable of 

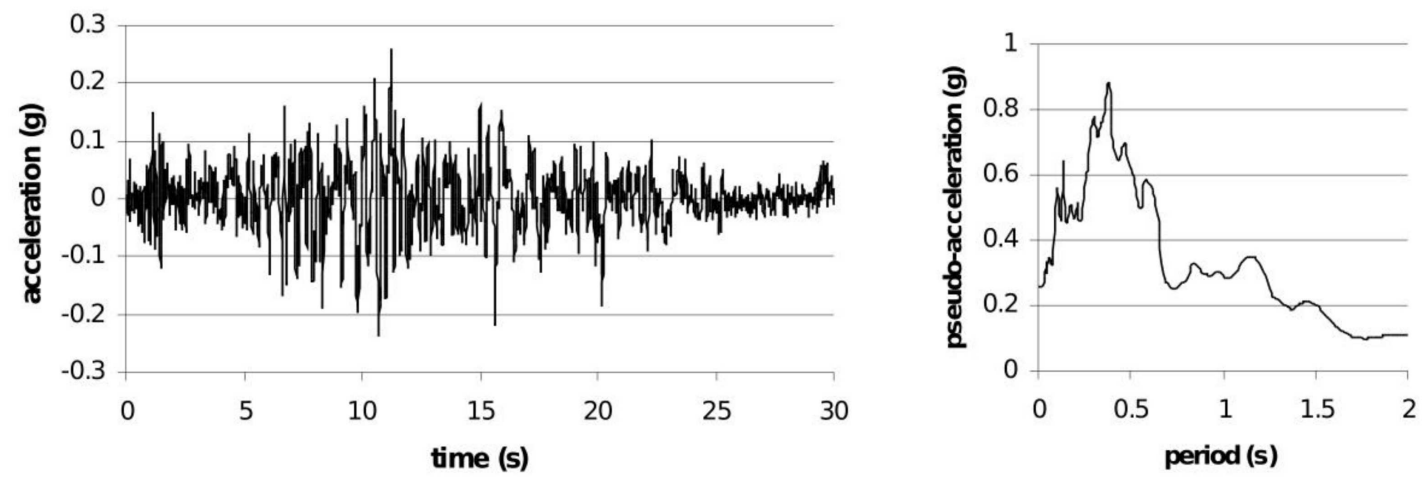

Figure 2: Acceleration time history recorded on the shaking table during the test and corresponding elastic response spectrum with a critical viscous damping ratio of $5 \%$.

representing the main energy dissipative phenomena likely to occur in concrete: appearance of permanent deformation, strain hardening and softening, stiffness degradation, local hysteresis loops, appearance of cracks. Its theoretical development and numerical implementation are based on thermodynamics with internal variables $[18,19]$ and on the finite element method with embedded strong discontinuities $[20,21,22]$. FEAP [23] is the finite element program used for the numerical implementation of the developments presented in this section.

\section{Enhanced kinematics:}

The first ingredient of this model is the definition of an enhanced kinematics that takes strong discontinuities into account. This is done, as depicted in Fig. 3 by writing the displacement field $u(\mathbf{x}, t)$ as the sum of a continuous displacement $\bar{u}(\mathbf{x}, t)$ - that is the displacement as it would be in the absence of strong discontinuity - and of displacement jumps $\overline{\bar{u}}_{i}(t)$ in sections $\Gamma_{i}$ of the solid domain $\Omega$ :

$$
u(\mathbf{x}, t)=\bar{u}(\mathbf{x}, t)+\sum_{i=1}^{n_{d i s}} \overline{\bar{u}}_{i}(t) \mathcal{H}_{\Gamma_{i}}(\mathbf{x})
$$

where $\mathcal{H}_{\Gamma_{i}}(\mathbf{x})$ is the Heaviside's function which, for a left-to-right oriented domain, is null on the left side of the discontinuity $\Gamma_{i}$ and unity on its right side.

With the hypothesis of small transformation, we have the following expression 


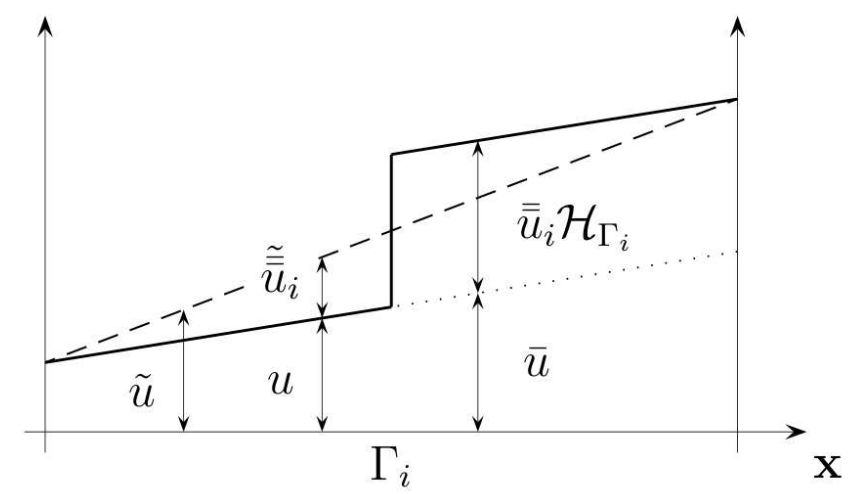

Figure 3: Construction of an enhanced displacement field $u(\mathbf{x}, t)$ as the sum of a continuous displacement $\bar{u}(\mathbf{x}, t)$ and of a displacement jump $\overline{\bar{u}}_{i}(t) \mathcal{H}_{\Gamma_{i}}(\mathbf{x})$ pertaining to discontinuity $\Gamma_{i}$.

for the normal strain field:

$$
\epsilon_{x x}\left(\bar{u}, \overline{\bar{u}}_{i}, t\right)=\frac{\partial \bar{u}(\mathbf{x}, t)}{\partial \mathbf{x}}+\sum_{i=1}^{n_{d i s}} \overline{\bar{u}}_{i}(t) \delta_{\Gamma_{i}}(\mathbf{x})
$$

where $\delta_{\Gamma_{i}}(\mathbf{x})$ is the Dirac's function.

\section{Stored energy function:}

When the Lagrange's variational principle is for instance chosen to derive the governing equations of the system (see Eq. (2) for the corresponding discretized form), the internal potential energy $U^{\text {int }}$ as to be written:

$$
\begin{aligned}
U^{i n t}(\bar{u}, \boldsymbol{\alpha}, t) & =\int_{\Omega} \psi(\bar{u}, \boldsymbol{\alpha}, t) d \Omega \\
& =\sum_{f=1}^{n_{f i b}^{c}} \int_{\Omega_{f}^{c}} \psi^{c}\left(\bar{u}, \boldsymbol{\alpha}^{c}, t\right) d \Omega_{f}^{c}+\sum_{f=1}^{n_{f i b}^{s}} \int_{\Omega_{f}^{s}} \psi^{s}\left(\bar{u}, \boldsymbol{\alpha}^{s}, t\right) d \Omega_{f}^{s}
\end{aligned}
$$

where $n_{f i b}^{c, s}$ is the total number of concrete or steel fibers, $\Omega_{f}^{c, s}$ is the volume of the fiber, $\psi^{c, s}$ is the stored energy function for concrete or steel which depends on the continuous displacement field $\bar{u}(\mathbf{x}, t)$ and on the set of internal variables $\boldsymbol{\alpha}^{c, s}$. Normal stresses are computed from these functions as

$$
\sigma_{x x}=\frac{\partial \psi}{\partial \epsilon_{x x}} .
$$




\section{Set of internal variables:}

The set of internal variables $\boldsymbol{\alpha}$ is defined to characterize the evolution of the main energy dissipative - inelastic - mechanisms which develop in the system. These internal variables are the memory of the system. The physical interpretation of each of them is provided in Fig. 4. Note that the constitutive law used here can handle different behavior in compression and tension, and can also reproduce a visco-elastic response (see [17] for a full description). Viscosity is not considered in this work and, for the sake of conciseness, we only focus on the compressive part of the behavior law in Fig. 4. The local admissible state of the system is expressed according to criteria functions in the stress-like domain of the set of variables dual to $\boldsymbol{\alpha}$. When irreversible mechanisms are activated in the structure, internal variables have to be updated and their evolution is governed by the principle of maximum dissipation. From the computational point of view, because we only consider linear hardening and softening laws, there is no need for local iteration when internal variables are updated, except for transitions between hardening and softening regimes, which leads to an efficient resolution procedure.

\subsection{Inelastic structural model}

The finite element mesh and the uniaxial constitutive laws for steel and both confined and unconfined concrete fibers used for the inelastic structural model of the $\mathrm{RC}$ frame are shown in Fig. 5. Material behavior laws have been identified to fit experimental monotonic $\left(\sigma_{x x}-\epsilon_{x x}\right)$ curves. The structure is assumed fixed at its base. Rigid end zones are defined to model the beam-to-column connections and rebar slip in surrounding concrete is not represented. These later hypotheses are questionable because the connections exhibit inelastic behavior during the test. This obvious limitations of the structural model has to be reminded when damping model is added in the simulation.

The loading time history consists in two successive phases: i) Static dead load is first applied step by step and then kept constant; ii) The seismic loading is applied. A first validation check of the inelastic structural model is carried out by simulating a free vibration test. Before dead load is applied, the elastic fundamental period of the structure is computed as $T_{1}^{e l a}=0.28 \mathrm{~s}$; then, due to the inelastic behavior of the structure, the elongated period is evaluated as $T_{1}^{i n i}=0.36 \mathrm{~s}$ when dead load is completely applied. Both $T_{1}^{\text {ela }}$ and $T_{1}^{\text {ini }}$ coincide with the experimental values. 


\begin{tabular}{|l|l|}
\hline $\boldsymbol{\alpha}$ & Phenomenological analogy \\
\hline $\bar{\epsilon}^{p}$ & plastic deformation \\
$\bar{\xi}^{p}$ & plastic isotropic strain hardening \\
$\bar{\lambda}^{p}$ & plastic kinematic strain hardening \\
$\bar{D}$ & damaged elastic compliance \\
$\bar{\xi}^{d}$ & damage isotropic strain hardening \\
$\overline{\bar{u}}^{p}$ & localized plastic displacement \\
$\overline{\bar{\xi}}^{p}$ & strain softening due to displacement localization \\
\hline
\end{tabular}
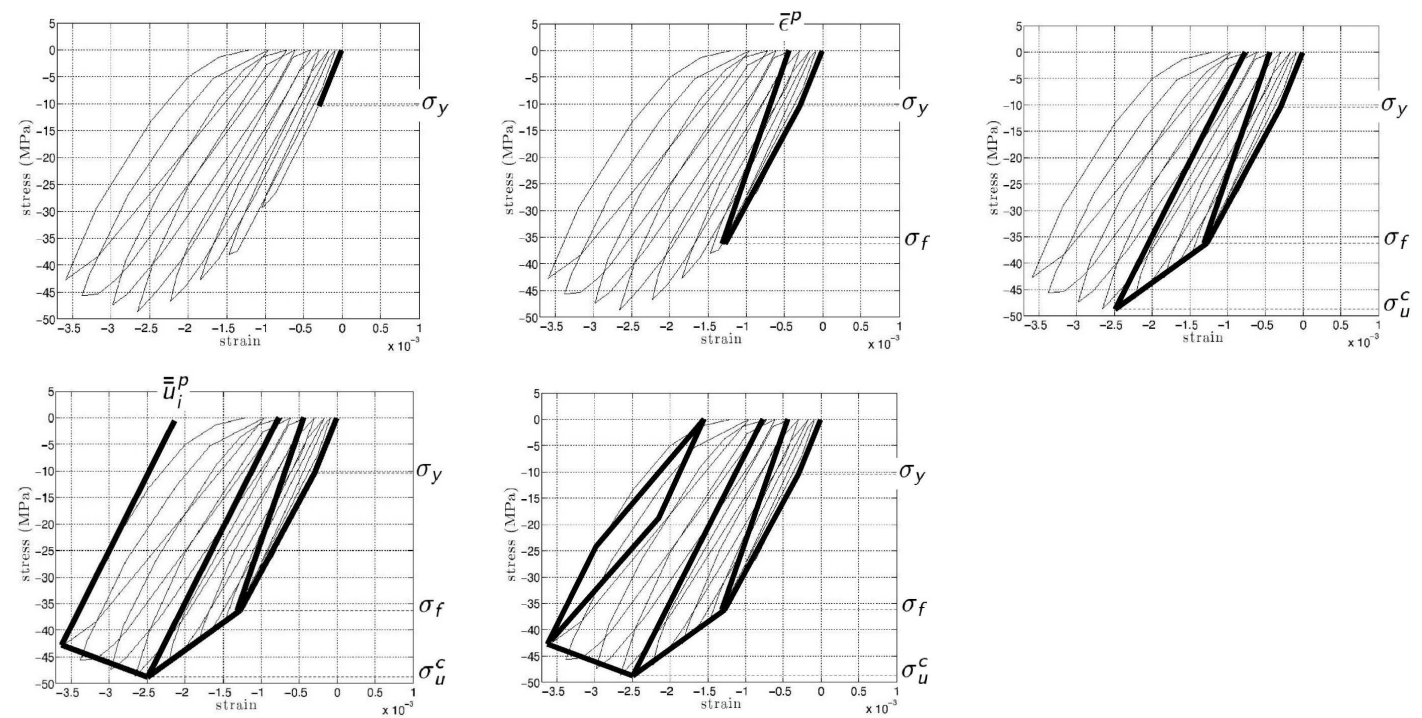

Figure 4: Internal variables for compression and their phenomenological interpretation. [top, left] Elastic response until yield stress $\sigma_{y}$ is reached. [top, centre] In the plastic domain, plastic deformation $\left(\bar{\epsilon}^{p}\right)$ and strain hardening $\left(\bar{\xi}^{p}\right)$ develop. [top, right] Once the limit stress $\sigma_{f}$ is reached, damage mechanisms are activated too, leading to a degradation of stiffness $(\bar{D})$ and a change in the strain hardening evolution $\left(\bar{\xi}^{d}\right)$. [bottom, left] Once the ultimate stress $\sigma_{u}$ is reached, deformation localizes $\left(\overline{\bar{u}}^{p}\right)$ and strain-softening is observed $\left(\overline{\bar{\xi}}^{p}\right)$. [bottom, center] Local hysteresis loops are represented with kinematic hardening in the plastic domain $\left(\bar{\lambda}^{p}\right)$. Note that each parameter of this model has a clear interpretation regarding the constitutive law to be identified. 

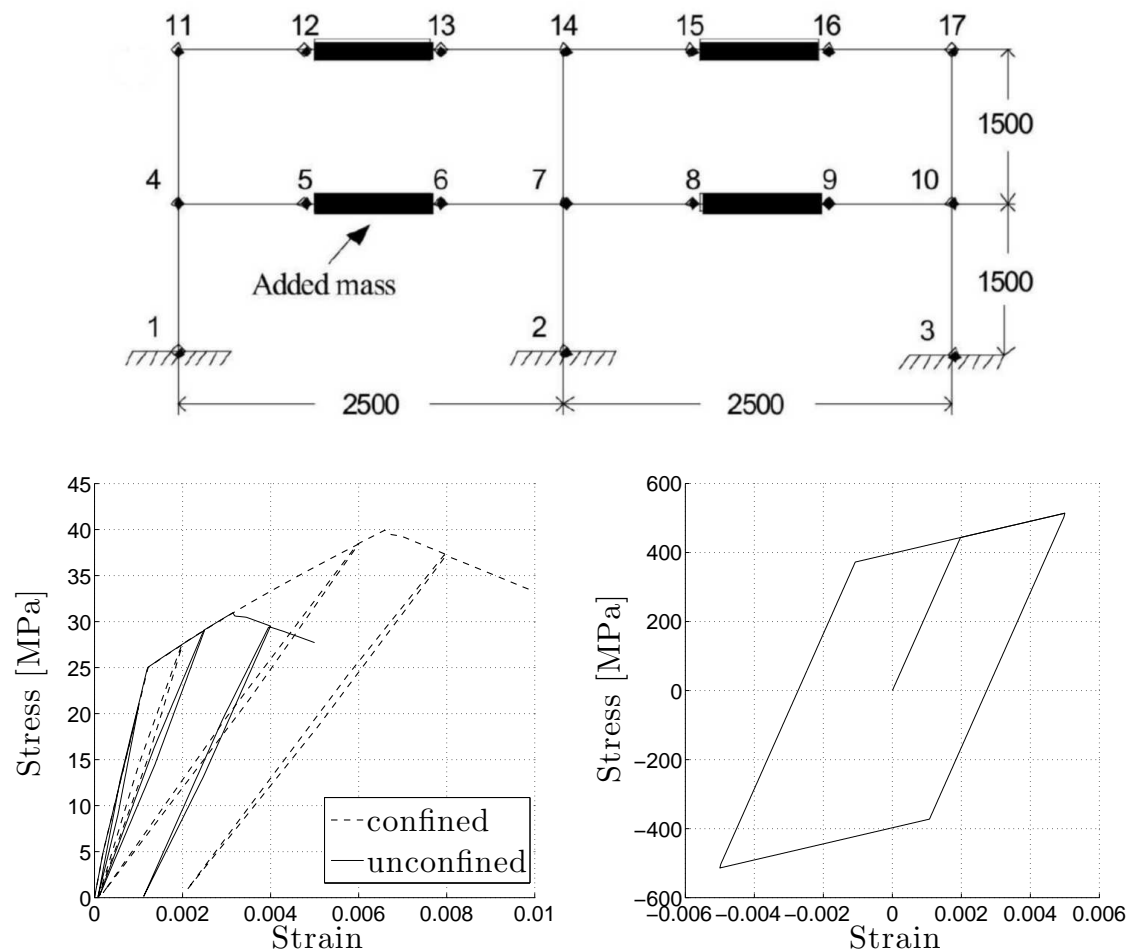

Figure 5: Finite element mesh (dimensions in [mm]) and material constitutive laws for the inelastic structural modeling. [bottom left] Confined and unconfined concrete behavior laws. [bottom right] Steel constitutive law.

\subsection{Proposition of a new family of Rayleigh damping models}

\section{Basic definitions:}

In the context of inelastic time history numerical analysis, the definition of damping might differ according to the reference cited. On the one hand, in [24], damping consists in both i) inherent damping resulting from the dissipation of energy by inelastic structural elements, and ii) additional viscous damping added in the simulation to take into account inherent energy dissipation sources not otherwise explicitly considered in the inelastic structural model. On the other hand, in [25], damping is defined as "the portion of energy dissipation that is not captured in the hysteretic response of components that have been included in the model", and it is then suggested in [25] to use "un-modeled energy dissipation" as a more appropriate terminology for damping. 
Because, in experimental investigations, measured damping results from all the energy dissipative phenomena, we herein decide to define damping as the combination of both hysteretic damping due to the energy dissipated by all the inelastic phenomena explicitly accounted for in the structural model and additional viscous damping that should be consistent with the inelastic structural model namely, that does not introduce energy dissipation already accounted for in the inelastic structural model.

\section{Problems encountered with Rayleigh damping:}

Controlling the amount of additional viscous damping energy dissipated in inelastic time history analyses is a very challenging task [11, 12, 13]. This is especially the case for commonly used Rayleigh proportional damping models, that is when the damping matrix is computed, in its most general form, as

$$
\mathbf{C}(t)=\alpha(t) \mathbf{M}+\beta(t) \mathbf{K}(t)
$$

where $\mathbf{K}(t)$ is the tangent stiffness matrix. Several researchers have provided insight in the comprehension of Rayleigh damping regarding the inelastic structural model it is coupled to, have highlighted limitations, and have eventually provided recommendations to cope with them $[11,12,13]$. Nevertheless, adding damping and controlling its consistency with the inelastic structural model still remains an issue to be addressed.

\section{Three common phases in seismic response:}

We now discuss in a qualitative way the notion of consistency for additional viscous damping. To that purpose, we start by stating that seismic structural response is composed by three main consecutive phases, as illustrated in Fig. 6. Both inelastic structural model and additional damping model must then be capable of representing the salient phenomena corresponding to each of these three phases. Foremost has to be properly modeled what we call here the "key window", namely the time interval within which the major inelastic modifications for structural performance assessment develop. For instance, key mechanisms that control near-collapse structural behavior are listed in [26]: degradation of strength and stiffness, and structure P-delta effects. From experimental results, we know that strain rate is another major issue.

A consistent additional damping model should be adapted to each of these three phases as follows: 


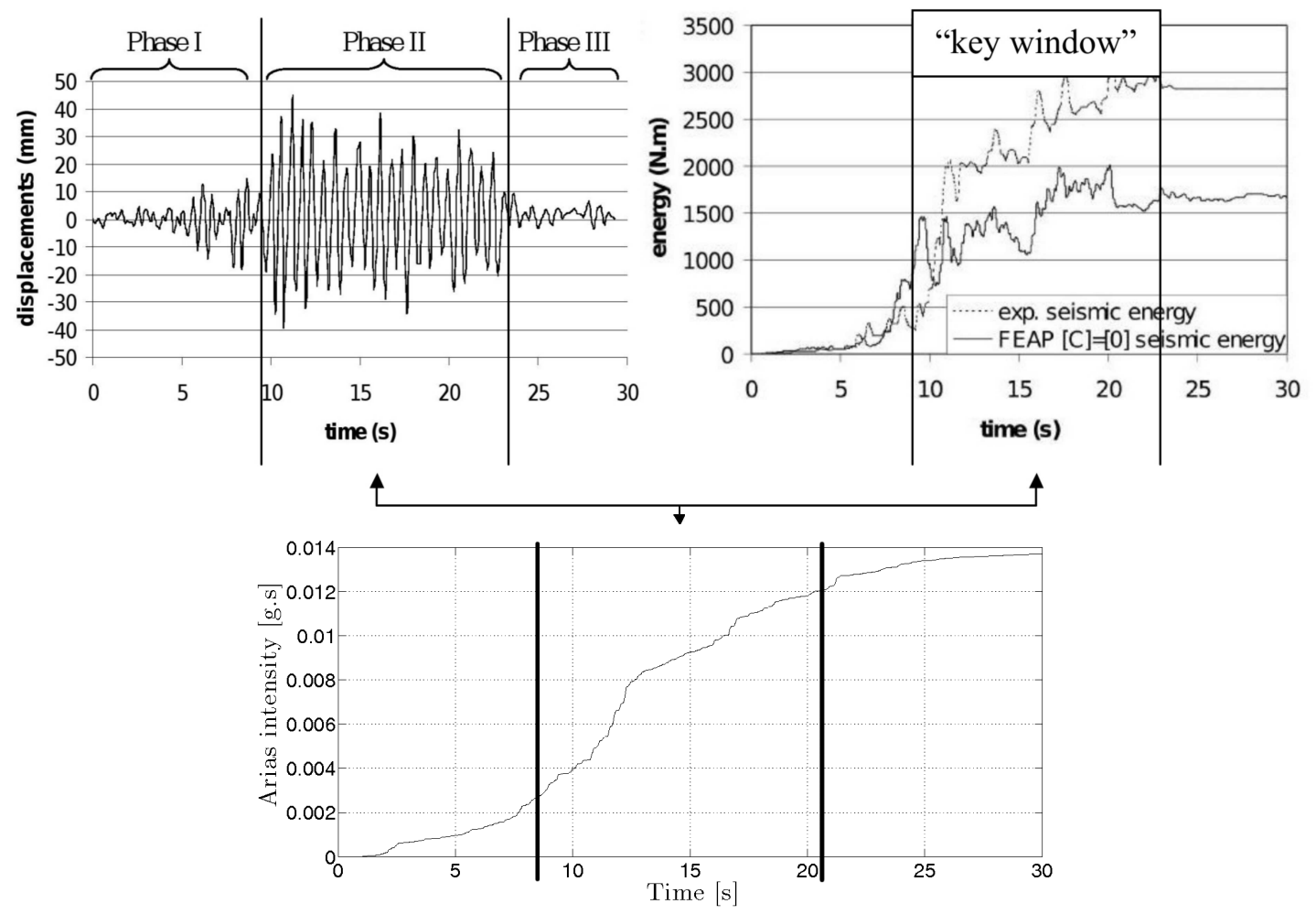

Figure 6: Three common phases in the seismic response and the concept of "key window". [top left] Structural relative displacement time-history. [top right] Total relative seismic energy time-history in the structure. [bottom] Arias intensity of the seismic signal: $A I(t)=\frac{\pi}{2 g} \int_{0}^{t} \ddot{u}_{g}^{2}(\tau) d \tau$.

- Phase 1: None or only few incursions in the inelastic domain occur. Energy dissipation in phase 1 thus comes from the friction in the cracks that appeared when applying dead load and from many other mechanisms always present in mechanical systems. When used, visco-elasticity and constitutive laws with local hysteresis $[27,17]$ in the structural model could account for these energy dissipation sources but a small amount of additional damping usually has to be added. For the RC frame considered in this work, a free-vibration test was carried out after dead load had been applied and a first modal damping ratio of $3.3 \%$ was measured [16].

- Phase 2: As the ground motion becomes stronger (at around $8 s$ in Fig. 6), an important amount of seismic energy is imparted to the structure and some parts of the structure then exhibit inelastic behavior. Inelastic struc- 
tural models are designed to explicitly model part of the numerous inherent nonlinear energy dissipative mechanisms involved in the structural response. The energy dissipation due to the mechanisms not explicitly accounted for in the inelastic structural model has to be introduced with the additional damping model.

- Phase 3: The structure has suffered irreversible degradations that modified its dynamic properties. Thus, even if the seismic demand is again as low as in phase 1, the energy dissipative mechanisms are different because of frictions in the cracks that appeared within phase 2 or at degraded bound between steel and concrete. Here again, visco-elasticity and behavior laws with local hysteresis $[27,17]$ in the structural model could account for these damping sources, but it generally has to be completed by additional damping.

\section{Proposition of a new family of Rayleigh damping models:}

In the following, two damping models will be used:

- A commonly used Rayleigh model based on tangent stiffness matrix and with two constant coefficients

$$
\mathbf{C}_{1}(t)=\alpha \mathbf{M}+\beta \mathbf{K}(t)
$$

- We propose a new family of models that is directly dependent on both the two key notions in the definition of the three phases introduced above: the capacity of the inelastic structural model to absorb energy and the seismic demand. The model is based on Rayleigh damping with tangent stiffness matrix and with coefficients adapted to each of the three phases:

$$
\mathbf{C}_{2}(t)=\alpha(t) \mathbf{M}+\beta(t) \mathbf{K}(t)
$$

The idea of adapting Rayleigh damping to the capabilities of the inelastic structural model for dissipating energy is present in the use of the tangent stiffness rather than the initial one: it is expected that the choice of tangent stiffness dependent damping will have the main advantage of providing the significant additional source of damping only in the domains/modes that are not accounted for by inelastic model. Such a choice allows to provide the physically based damping phenomena interpretation, which leads to damping coefficients that are easier

to identify. The same idea has been further exploited in [28] where $1 \%$ viscous damping is added to an inelastic dam model before cracking and $10 \%$ after cracking to represent localized high dissipation by friction between crack lips. Another 
instance is the work presented in [29] where viscous damping is added only in the shear wall zones which remain elastic, while no damping is added in the inelastic zones where the structural model is let alone to dissipate the seismic energy.

In spite of its stronger physical background, implementing damping model $\mathbf{C}_{2}(t)$ is not as straightforward as damping model $\mathbf{C}_{1}(t)$. First, three sets of Rayleigh coefficients $\left(\alpha_{p}, \beta_{p}\right)_{p=1,2,3}$ corresponding to each of the three phases $p$ have to be identified to define the appropriate damping ratios. Second, the instants which delimit the three phases have to be determined, which can be automatically accomplished by the computer program that is capable of detecting the activation of significant inelastic behavior.

\subsection{Calibration and validation of the models}

Seismic inelastic time history analyses of the RC frame have been carried out with the inelastic structural model presented above coupled to either additional damping model $\mathbf{C}_{1}(t)$ or $\mathbf{C}_{2}(t)$. The implicit Newmark integration scheme with parameters $\beta=0.25$ and $\gamma=0.5$ is used with a time step of $0.005 \mathrm{~s}$. Fig. 7 shows a comparison between the simulated top-displacement and energies time histories and the respective experimental results reproduced from [30]. Good agreement between simulated and experimental data can be observed. Moreover, there is very good agreement between the hysteretic plus elastic $\left(E_{H}\right)$ and damping $\left(E_{D}\right)$ energy quantities computed with the models proposed here and an analogous Perform3D [31] simulation we carried out for comparison purpose, namely $E_{H} \approx 550 \mathrm{~N}$.m and $E_{D} \approx 2250 N . m$, corresponding to approximately $20 \%$ and $80 \%$ of the total work done by the structure during seismic motions. Last, the fundamental period of the $\mathrm{RC}$ frame in post-earthquake conditions is estimated by a free-vibration test performed at the end of the seismic signal and it is observed that simulated value is $T_{1}^{s i m}=0.45 \mathrm{~s}$ whereas the experimental measure comes to $T_{1}^{e x p}=0.55 \mathrm{~s}$. This shows, as expected by regarding the limitations of the structural model used (elastic beam to column connections and no rebar slip), that not all structural stiffness degradation mechanisms are always well represented by the inelastic structural model. In particular, the joints and supports often need special attention and more elaborate models.

For damping model $\mathbf{C}_{1}(t)$, the good results shown in Fig. 7 have been obtained with $\alpha$ and $\beta$ computed so that $\xi_{1}=\xi_{2}=3.3 \%$. For damping model $\mathbf{C}_{2}(t)$, curves plotted in Fig. 7 have been obtained with the following parameters identified so as to obtain good match between experimental and simulated responses:

- Phase 1: from $0 \leq t \leq t_{1}, \xi_{1}=\xi_{2}=1.0 \%$. $t_{1}$ is defined such that two 

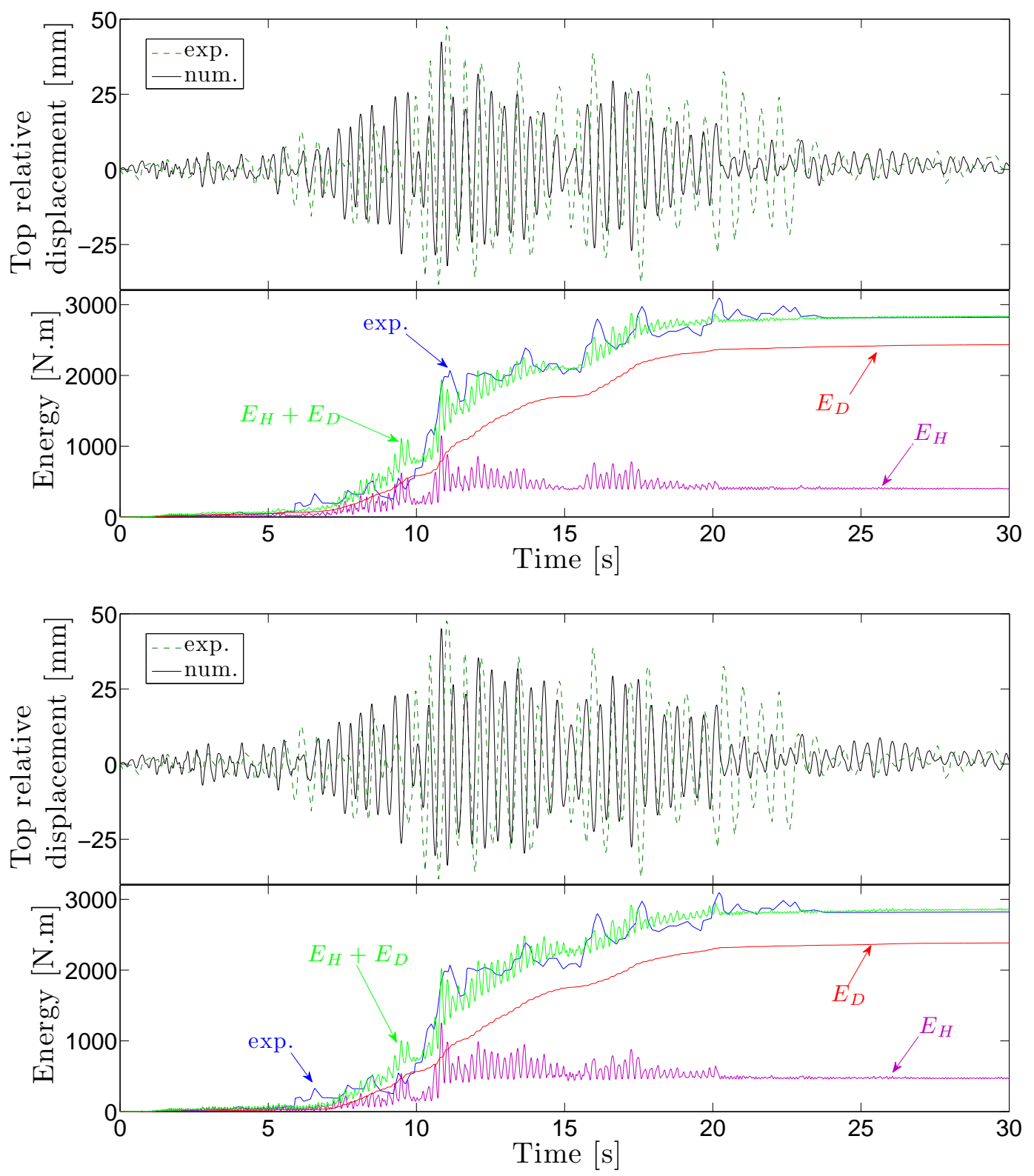

Figure 7: Experimental and simulated top-displacement; simulated hysteretic plus elastic energies $\left(E_{H}\right)$, simulated additional damping energy $\left(E_{D}\right)$, and both experimental and simulated total internal work. [top] With common added damping model $\mathbf{C}_{1}(t)$; [bottom] With the proposed new family of Rayleigh damping models $\mathbf{C}_{2}(t)$. The structural responses shown here for damping models $\mathbf{C}_{1}(t)$ and $\mathbf{C}_{2}(t)$ looks very similar because both models have been calibrated to experimental data; however, model $\mathbf{C}_{2}(t)$ has more capability for representing transient evolution of added damping. 
conditions are satisfied. First, the hysteretic energy which is dissipated by the inelastic response of the structural model has to reach - for the frame considered in this work -150 N.m. Then, the seismic demand must be such that the increase in Arias intensity $A I[32]$ within the time range $\left[t_{1} ; t_{1}+10 \times\right.$ $\left.T_{1}^{i n i}\right]$ is larger than $0.0025 \mathrm{~g} . \mathrm{s} ; T_{1}^{i n i}$ is the fundamental period of the structure after dead load has been applied and before the earthquake $\left(T_{1}^{i n i}=0.36 \mathrm{~s}\right.$ for the structure considered here).

- Phase 2: from $t_{1} \leq t \leq t_{2}, \xi_{1}=\xi_{2}=4.0 \%$. $t_{2}$ is defined as $t_{2}=t_{1}+10 \times T_{1}^{\text {ini }}$.

- Phase 3: from $t_{2} \leq t \leq \bar{T}, \xi_{1}=\xi_{2}=2.5 \%$, where $\bar{T}$ is the duration of the seismic signal.

It might happen that one of these two criteria is never satisfied within the earthquake duration. In such a case, only phase 1 is effectively active throughout the analysis.

In the rest of this chapter, we focus only on the new model with changing coefficients, for it is very likely to deliver better prediction from the standard Rayleigh damping models given its more sound physical basis. The damping parameters defined above are expected to be suitable to model the response of the frame structure for every seismic signal that will be used in the next sections, as we usually proceed with damping model $\mathbf{C}_{1}(t)$. In the next sections, we then investigate likely consequences of using damping model $\mathbf{C}_{2}(t)$ instead of $\mathbf{C}_{1}(t)$ when it comes to structural fragility analysis.

\section{Selection of a set of real ground motions}

Following [33], there are three basic options available for obtaining accelerograms for inelastic time-history analysis: i) to use spectrum-compatible synthetic accelerograms with realistic energy, duration and frequency content; ii) to use synthetic accelerograms generated from seismological source model and accounting for path and site effects; and iii) to use real accelerograms recorded during earthquakes. We chose this latter option and present in the following how we proceed to select ground motion time histories in the PEER ground motion database [34].

\subsection{Likely earthquake scenarios in the Cascadia subduc- tion zone}

Ground motion time history recorded from the Olympia, Washington 1949 earthquake has been used for the shaking table test at École Polytechnique of Montreal 
[16]. It is then assumed that the frame structure considered in this investigation is located in the Cascadia subduction zone. The Western margin of the North American plate - from the North of California state up to Vancouver island, British Columbia, Canada - is characterized by the so-called Cascadia subduction zone, where it is subducted by the Juan de Fuca plate beneath the Pacific ocean.

The seismic activity in the Cascadia subduction zone has been investigated for several decades $[35,36,37,38]$. Three types of earthquakes are produced in this zone:

- Shallow crustal earthquakes are associated to surface faults in the American continental plate with magnitude $M_{w}$ larger than 7.0 and hypocenter depth less than $30 \mathrm{~km}$;

- Thrust interplate or interface earthquakes are due to differential motion in the interface between the Juan de Fuca and the North American plates. They happen offshore with surface hypocenter, generally with depth less than 30 $\mathrm{km}$. The Cascadia subduction zone has the potential to produce a large event of $M_{w}=8.3 \pm 0.5$;

- Intraplate or intraslab earthquakes occur deep within the Cascadia subduction zone (depth $>40 \mathrm{~km}$ ) beneath the Puget Sound of Western Washington state. These types of earthquakes have occurred frequently including in 1949 Olympia $\left(M_{w}=6.8\right), 1965$ Seattle-Tacoma $\left(M_{w}=6.8\right), 1999$ Satsop $\left(M_{w}=5.9\right)$ and 2001 Nisqually $\left(M_{w}=6.8\right)$;

- No seismicity has been observed for depth larger than $100 \mathrm{~km}$.

\subsection{Search for a real ground motions dataset}

To that purpose, we use the PEER ground motion database with its Web application [34]. Currently, this database is limited to recorded time series from shallow crustal earthquakes only. A basic criterion used by the Web application to select a representative acceleration time history is that its elastic response spectrum provides a good match to a user target spectrum over a range of periods of interest. We define the target spectrum as the elastic response spectrum corresponding to the feedback accelerogram recorded on the shaking table during the test (see Fig. 2). The Web application allows for assigning different weights to different period ranges so that the matching process is guided by the period ranges with the higher weights. In our case, the response of the structure is governed by its first eigenmode and the fundamental period was experimentally measured to vary within the range $0.36 s \leq T_{1} \leq 0.55 \mathrm{~s}$ corresponding to the pre- and post-seismic states. We 
consequently favor the target and actual spectra to match within this period range.

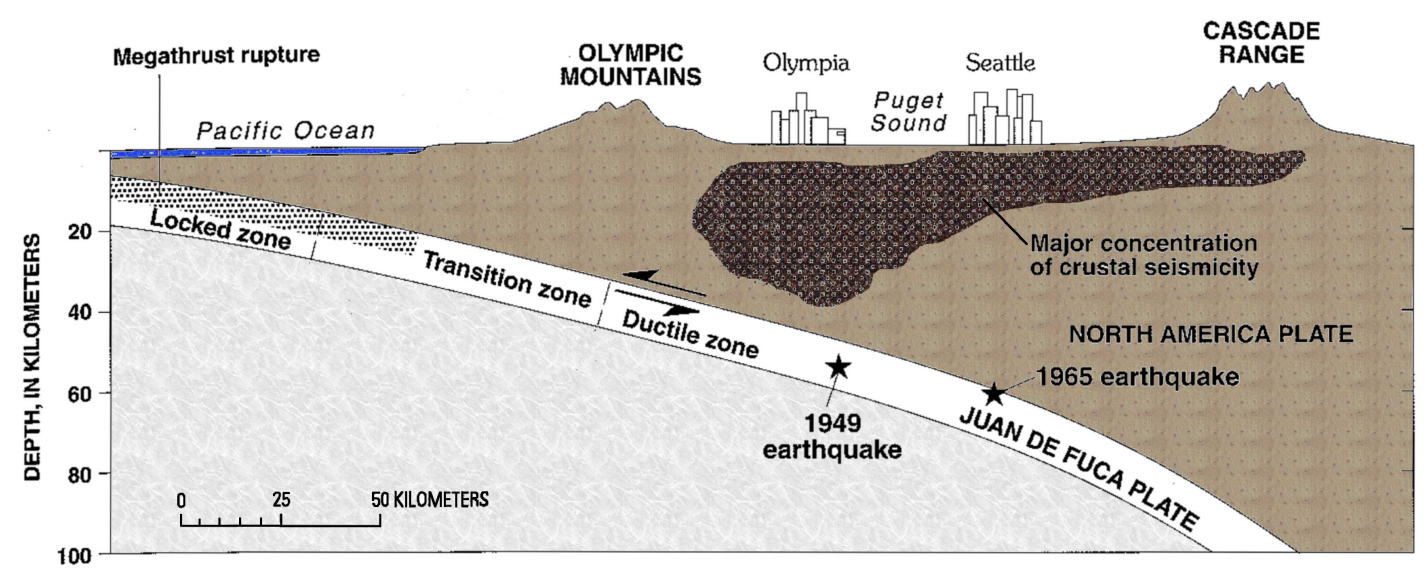

Figure 8: Cross section of the Cascadia subduction zone (adapted from [36]).

Table 1: Geologic profile for the Olympic Highway Test Lab strong-motion recording site in Washington [36]. $v_{s}$ is the shear wave velocity and $\rho$ the density.

\begin{tabular}{|c|c|c|c|c|}
\hline $\begin{array}{c}\text { Depth } \\
{[\mathrm{m}]}\end{array}$ & Geology & Description & $\begin{array}{c}v_{s} \\
{[\mathrm{~m} / \mathrm{s}]}\end{array}$ & $\begin{array}{c}\rho \\
{\left[\mathrm{kg} / \mathrm{m}^{3}\right]}\end{array}$ \\
\hline $0-3$ & Fill & Loose sand & 165 & 1500 \\
\hline $3-12$ & Deposits & Medium dense fine to medium sand & 220 & 1500 \\
\hline $12-20$ & Deposits & $\begin{array}{c}\text { Interbedded very stiff to hard } \\
\text { sandy silt and very dense silty fine } \\
\text { to medium sand }\end{array}$ & 270 & 1500 \\
\hline $20-41$ & Deposits & (same as layer just above $)$ & 330 & 1500 \\
\hline
\end{tabular}

Then, several parameters - or acceptance criteria - can be input into the Web application to characterize the likely earthquake scenarios of interest for the study. According to i) what was stated in the previous section 4.1, ii) the cross section of the Cascadia subduction zone depicted in Fig. 8, and iii) the geological profile of the Puget Sound region described in Tab. 1, we define suitable ranges for these parameters as summarized in Tab. 2. Practically, due to the above-mentioned current limitation of the PEER database, we only look for ground motion records corresponding to shallow crustal earthquakes. 
Table 2: Acceptance criteria for initial ground motions search with the PEER database Web application [34]. $M_{w}$ is the moment magnitude, $R_{J B}$ is the JoynerBoore distance, $R_{\text {rup }}$ is the closest distance to rupture plane and $v_{s 30}$ is the average shear wave velocity in the top 30 meters of the site. All fault types are considered.

\begin{tabular}{|lr|c|c|c|}
\hline Earthquake: & crustal & interface & intraslab \\
\hline$M_{w}$ & & {$[7.0,9.0]$} & {$[7.8,8.8]$} & {$[5.5,7.0]$} \\
$R_{J B}$ & {$[\mathrm{~km}]$} & {$[0,150]$} & {$[30,200]$} & {$[30,200]$} \\
$R_{\text {rup }}$ & {$[\mathrm{km}]$} & {$[0,150]$} & {$[30,100]$} & {$[30,100]$} \\
$v_{s 30}$ & {$[\mathrm{~m} / \mathrm{s}]$} & {$[0,200]$} & {$[0,200]$} & {$[0,200]$} \\
\hline
\end{tabular}

Because a first search with these criteria led to a selection of around 20 earthquakes only, we proceeded to a second search with the range of allowed moment magnitudes extended to $6.0 \leq M_{w} \leq 9.0$. Then, we only retained 48 earthquakes which had the best fitting coefficients with the target response spectrum and finally multiply each of them by a scale factor of 5.0. Note that PEER ground motion database provides the fault normal (FN) and fault parallel (FP) components of the seismic signal and that the 48 records we selected either corresponds to the $\mathrm{FN}$ or FP component pertaining to 48 different earthquakes.

\section{$5 \quad$ Seismic fragility analysis}

In this section, we focus on the vulnerability analysis of the test RC frame structure presented in section 2. Uncertainty is only considered in the seismic loading: the selected time-history ground motions that are likely to occur in the Cascadia subduction zone are used as inputs of inelastic time-history deterministic simulations to compute fragility curves. The damping model - either $\mathbf{C}_{1}(t)$ or $\mathbf{C}_{2}(t)$ - is the only variable considered in the RC frame model.

\subsection{Theoretical background}

Structural vulnerability analysis is evaluated here by computing fragility curves which provide the conditional probability for a structure to sustain a given damage level for a given earthquake intensity. Following [39], it is assumed that the fragility curve can be expressed in the form of a two-parameter lognormal distribution function. The estimation of these two parameters is then performed with the maximum likelihood method. 
Let consider a sample of $n$ independent observations $x_{j}$ that can be classified in two classes as "success" $\left(x_{j}=1\right)$ and "failure" $\left(x_{j}=0\right)$. Let also consider that each realization $x_{j}$ has a relative frequency of success equal to $F\left(I M_{j}, \theta\right)$, that is a function that depends on the intensity measure $I M_{j}$ associated to each realization $x_{j}$ and of a set of parameters $\theta$. Then, the probability of observing a set of realizations $\mathbf{x}=\left(x_{1}, \ldots, x_{n}\right)$ composed of $p$ successes $x_{1}, \ldots, x_{p}$ and $n-p$ failures $x_{p+1}, \ldots, x_{n}$, whatever the order, is $([40], \mathrm{p} .77)^{1}$ :

$$
f(\mathbf{x} \mid \theta)=\frac{n !}{p !(n-p) !}\left(F\left(I M_{j}, \theta\right)\right)^{p} \cdot\left(1-F\left(I M_{j}, \theta\right)\right)^{n-p}
$$

The problem one has to solve can be expressed as: Given the observed data $\mathbf{x}$, find the set of parameters $\theta$ that is most likely to have produced these observed data. To solve this inverse problem, we define the likelihood function as a function of $\theta$ given $\mathbf{x}$ :

$$
\mathcal{L}(\theta \mid \mathbf{x})=f(\mathbf{x} \mid \theta)
$$

The principle of maximum likelihood estimation states that: given the data $\mathbf{x}$ actually observed, the set of parameters $\theta$ looked for is the one that makes $\mathbf{x}$ the most likely data to be observed. $\theta$ can thus be identified by maximizing the likelihood function $\mathcal{L}$. For computational convenience, the $\log$-likelihood $\ln \mathcal{L}(\theta \mid \mathbf{x})$ is introduced and maximized, which provides the same estimators because $\ln x$ is a monotonic function. The problem one has to solve thus reads:

$$
\theta_{e}=\underset{\theta}{\operatorname{argmax}} \ln \mathcal{L}(\theta \mid \mathbf{x})
$$

Under the lognormal assumption, the fragility curve for a particular damage index $D I_{i}$ - defining what is "success" and "failure" - is defined as:

$$
F\left(I M_{j}, \theta_{e}\right)=\phi\left(\frac{1}{\zeta_{e}} \ln \frac{I M_{j}}{c_{e}}\right)=P\left[D I \geq D I_{i} \mid I M_{j}\right]
$$

where $\theta_{e}=\left\{\zeta_{e}, c_{e}\right\}$ is the set of estimated parameters and $\phi(\cdot)$ is the standardized normal distribution function.

Constructing fragility curves in such a framework raises issues concerning their statistical significance. In [39], Shinozuka et al. provide tools to test the goodness of fit between the inferred fragility curve and the realization of the random variable $X_{j}$ following Bernoulli distribution: $X_{j}=1$ when the damage index is reached and $X_{j}=0$ otherwise. They also present a Monte Carlo technique they use to

\footnotetext{
${ }^{1}$ Henri Poincaré (1854-1912) is a French mathematician, physician and philosopher. This year is the hundredth anniversary of his death.
} 
demonstrate the extent of the statistical variations in the estimators $\theta$. Another very important contribution for the statistical analysis of fragility curves is the work of Sáez et al. [6]. They show how to compute the amount of Fisher information about the set of parameters $\theta$ - the terms of the Fisher information matrix being by definition $\mathcal{F}_{i j}(\theta)=\operatorname{cov}\left(\frac{\partial \ln \mathcal{L}}{\partial \theta_{i}} ; \frac{\partial \ln \mathcal{L}}{\partial \theta_{j}}\right)$, where $\operatorname{cov}(\cdot)$ denotes the covariance - which is provided by the ground motions used to construct fragility curves, and then how to compute a lower bound for the standard deviation of the elements of $\theta_{e}$. This method thus provides a way to somehow measure the ability of the data to estimate $\theta$.

\subsection{Intensity measures and structural damage indices}

To characterize the seismic ground motion time-histories used for structural vulnerability analysis, they are assigned intensity measures $(I M) .18$ of them are reviewed in [41] in the context of the issue of selecting earthquakes for incremental dynamic analysis of inelastic steel frame structures. $44 I M$ are reviewed or proposed for masonry structures in [42]. Among the most common $I M$, one finds: the peak ground acceleration $(P G A)$; the acceleration at the fundamental period $S_{A}\left(T_{1}, 5 \%\right)$; the Arias intensity $(A I)$ which is effectively a measure of the total energy in the ground motion and computed as

$$
A I(t)=\frac{\pi}{2 g} \int_{0}^{t} \ddot{u}_{g}^{2}(\tau) d \tau ;
$$

the significant duration $D_{5-95}$, which the time needed to build up between $5 \%$ and 95\% of the total Arias intensity. Other measures are: the root mean square of acceleration (RMSA) computed as [41]:

$$
R M S A=\sqrt{\frac{1}{\tau_{d}} \frac{2 g}{\pi} A I}
$$

where $\tau_{d}$ is an effective duration of the record, taken here as $D_{5-95}$; spectrum intensities such as [42]:

$$
S I_{V}=\int_{T_{a}}^{T_{b}} S_{V}(T, \xi) d T,
$$

where $S_{V}$ is the spectral velocity at period $T$ and with damping $\xi$. Here, we take $T_{A}=0.36 \mathrm{~s}$ and $T_{B}=0.55 \mathrm{~s}$ which are the fundamental periods in pre- and postearthquake conditions. For fragility surfaces, Seyedi et al. [5] chose the spectral displacement $S_{D}\left(T_{1}\right)$ and $S_{D}\left(T_{2}\right)$ where $T_{1}$ and $T_{2}$ are the two main eigenperiods in the direction along which the ground motions are applied. 
Then, to characterize the structural response, damage indices $(D I)$ are used. One can distinguish between three categories: i) $D I$ computed from energy quantities such as the Park-Ang-Wen damage accumulation model [43] or the normalized hysteretic energy used in [44] or [41]; ii) Other DI based on quantities directly related to the structural inelastic response such as the ductility demand [41], the cumulative ductility index as defined in [44] or the maximum strength degradation ratio [42]; iii) Other quantities not necessarily pertaining to - but affected by - the inelastic structural behavior such as the maximum relative roof displacement $(M R D)$ or the maximum inter-story drift ratio $(M I S D R)$. To these two latter indices, because particular attention is paid in this work on the energy dissipated by both the damping and the inelastic structural models, we also compute the amount of hysteretic energy $\left(E_{H}\right)$ dissipated by the inelastic mechanisms explicitly accounted for in the structural model and the amount of damping energy $\left(E_{D}\right)$, as well as their respective ratio $E_{H, D} R=E_{H, D} /\left(E_{H}+E_{D}\right)$.

\subsection{Fragility curves}

We first investigate in Table 3 the correlation between the intensity measures and damage indices considered in this work, when a linear model is used to predict a $D I$ from an $I M$. Correlation is the lowest for intensity measure $D_{5-95}$ because there is no explicit influence of the earthquake duration in the various $D I$ considered. The correlation for the energy ratios is poor for all the $I M$ considered, which is not the case for the dissipated energy quantities where, in particular, correlation is good with the energy contained in the seismic signal $(A I)$. The very good correlated maximum roof displacement and spectral displacement at fundamental period $T_{1}$ with $5 \%$ viscous damping - as depicted in Fig. 9 - will be used in the following to construct fragility curves.

In Fig. 9, one can see an obvious tendency to obtain larger maximum roof displacement with damping model $\mathbf{C}_{2}(t)$. Constructing fragility curves for a given $M R D$ level along with a proper statistical analysis provides another way to infer some likely consequences of using a damping model instead of another. To that purpose, Fig. 10 shows the fragility curves (solid lines) pertaining to $D I$ $M R D \geq 40 \mathrm{~mm}$ obtained with both damping models $\mathbf{C}_{1}(t)$ and $\mathbf{C}_{2}(t)$. Dashed lines approximately represent the smallest area the fragility curves would describe when its parameters $\theta=\{\zeta, c\}$ varies around $\theta_{e}=\left\{\zeta_{e}, c_{e}\right\}$ plus or minus their standard deviation. Dashed lines are constructed as in [6], relying on the inverse of the Fisher information matrix provided by the selected ground motion about $\theta$.

From Fig. 10, one can infer that the additional damping model entails very 
Table 3: Square of the coefficient of correlation $R^{2}$ (in \%) between actual $D I$ and $D I$ obtained from a linear model between $I M$ and $D I$, for added damping models $\mathbf{C}_{1}(t) / \mathbf{C}_{2}(t)$.

\begin{tabular}{|l|c|c|c|c|c|}
\hline & $M R D$ & $M I S D R$ & $E_{D / H} R$ & $E_{D}$ & $E_{H}$ \\
\hline$P G A$ & $73 / 71$ & $71 / 69$ & $3.5 / 0.6$ & $51 / 52$ & $36 / 37$ \\
\hline$A I$ & $68 / 68$ & $68 / 68$ & $9.1 / 5.9$ & $86 / 83$ & $61 / 62$ \\
\hline$D_{5-95}$ & $8 / 7$ & $8 / 7$ & $1.3 / 1.0$ & $1 / 1$ & $2 / 2$ \\
\hline$R M S A$ & $75 / 73$ & $74 / 73$ & $8.2 / 4.5$ & $57 / 55$ & $43 / 45$ \\
\hline$S_{A, V, D}\left(T_{1}, 5 \%\right)$ & $85 / 82$ & $84 / 82$ & $5.7 / 2.6$ & $68 / 68$ & $53 / 55$ \\
\hline$S I_{A, V, D}(5 \%)$ & $77 / 74$ & $77 / 75$ & $8.5 / 4.6$ & $57 / 57$ & $48 / 51$ \\
\hline
\end{tabular}

significant uncertainty in structural fragility analysis of inelastic RC frame structures. Fig. 11 is shown to provide better insight into the discrepancies one can expect to observe in the structural response when either damping model $\mathbf{C}_{1}(t)$ or $\mathrm{C}_{2}(t)$ is used. Both seismic signals considered have the same intensity measure $S_{A}\left(T_{1}, 5 \%\right)=0.51 \mathrm{~g}$. For the analysis in concern on the left part of Fig. 11, either the maximum capacity of the structure to store hysteretic energy $E_{H}=150 \mathrm{~N}$. $\mathrm{m}$ or the minimum seismic demand $0.0025 /\left(t_{2}-t_{1}\right)$ is not reached, so that, for damping model $\mathbf{C}_{2}(t)$, only the phase 1 with $\xi_{1}=\xi_{2}=1 \%$ is effectively active throughout the analysis; this makes both damping models analogous but with critical damping ratios in sharp contrast $-3.3 \%$ against $1 \%$ - leading to very different structural responses. For the analysis in concern on the right part of Fig. 11, phase 2 begins at $t_{1}=15.4 \mathrm{~s}$ until $t_{2}=19 \mathrm{~s}$. Both models predict almost identical $M R D$ but oscillation amplitude is more rapidly attenuated for model $\mathbf{C}_{1}(t)$.

\section{Conclusions and perspectives}

The inelastic structural response in seismic loading results from the combination of an inelastic structural model with an added damping model. The damping model has to be consistent with the inelastic structural model, which implies that it has, and only has, to model the energy dissipation sources not otherwise explicitly accounted for in the inelastic structural model, nothing more or less. Rayleigh damping models are the most commonly used for earthquake engineering applications, although it is well established that controlling the amount of energy dissipation these models introduce throughout inelastic time history simulations is difficult to achieve. 


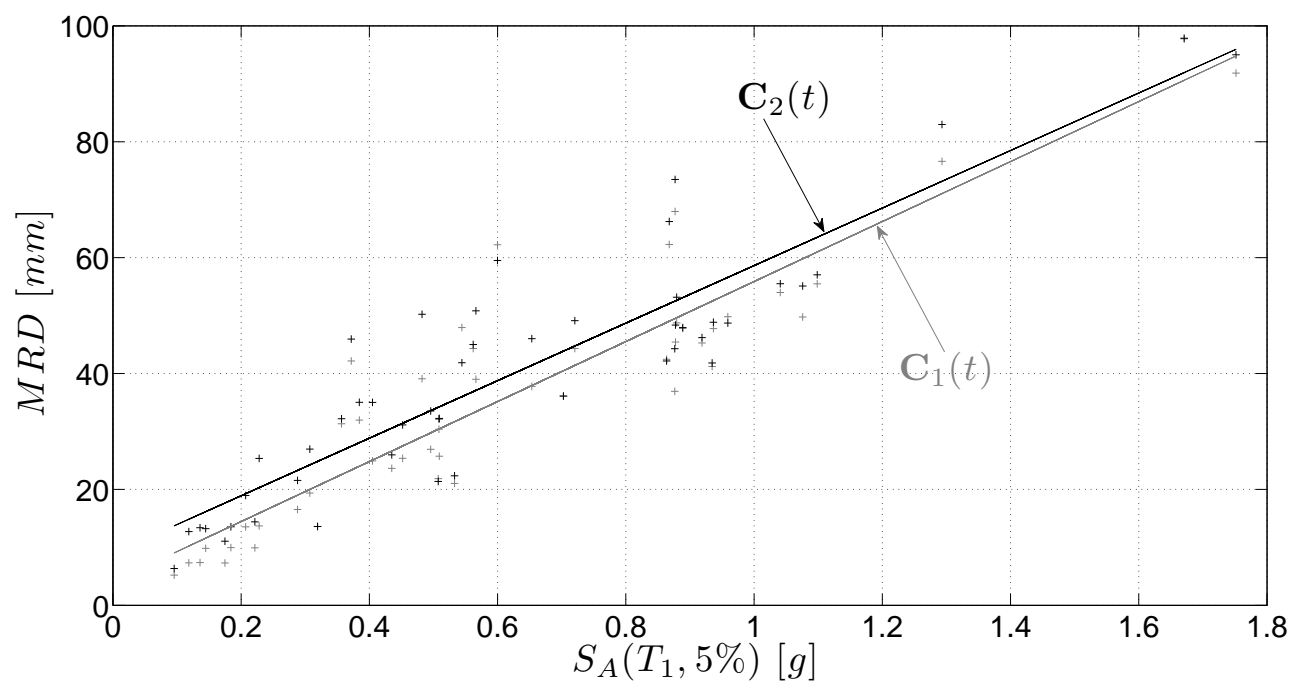

Figure 9: Linear model between $S_{A}\left(T_{1}, 5 \%\right)$ and $M R D$ for both damping models $\mathbf{C}_{1}(t)$ and $\mathbf{C}_{2}(t)$.

On another hand, inelastic time history analyses are widely used for structural fragility assessment in seismic loading. Uncertainties arising from the seismic signal likely to excite a building in a given geographical region as well as from the lack of knowledge on the structural parameters which characterize the inelastic structural model have both been considered in structural fragility analyses. On the opposite, the damping model is scarcely considered as a source of uncertainty; moreover, when it is the case, the damping ratio is assigned a probabilistic distribution but whether commonly used added damping models are suitable or not is an issue that is not regarded. This is the issue addressed in the work presented above.

In this chapter, we propose a new family of Rayleigh damping models that relies both on the capacity of the inelastic structural model to absorb energy and on the seismic demand and compare it to a commonly used Rayleigh model in the context of the fragility analysis of a $\mathrm{RC}$ moment-resisting frame. Its inelastic response is modeled by fiber elements using a constitutive law recently developed by the authors [17]. The structure is supposed to be built in the Cascadia subduction zone, a seismically active zone in the South-West of Canada and the North-West of the USA. From this comparative analysis, it can be inferred that the added damping model entails very significant uncertainty in structural fragility analysis of inelastic RC frame structures. 


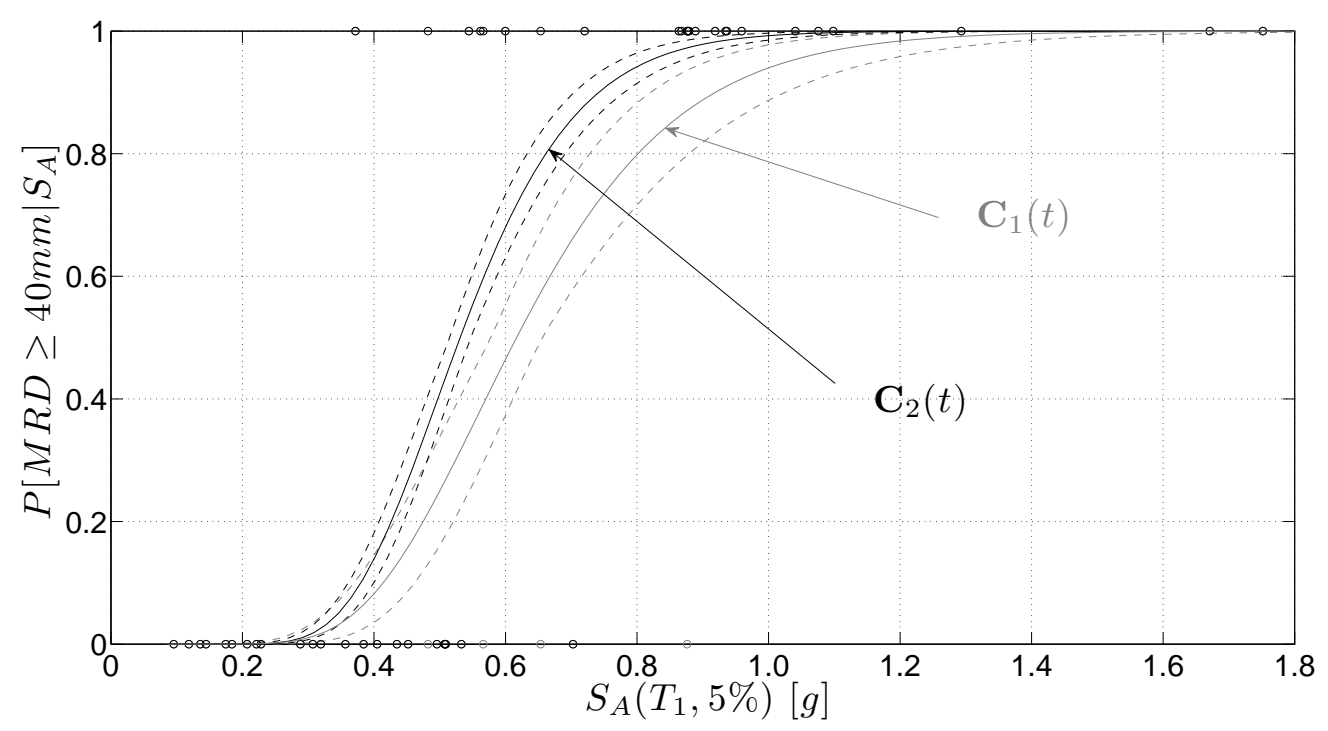

Figure 10: Structural fragility curves (solid lines) for both damping models $\mathbf{C}_{1}(t)$ and $\mathbf{C}_{2}(t)$. Dashed lines are plotted according to the method presented in [6] and show that, for the $D I$ level considered here, the fragility curves are constructed from a number of ground motions which is sufficient for drawing pertinent conclusions from this comparative study. Circles represent the realizations of the Bernoulli random variable $X_{i}=1$ when $R M D_{i} \geq 40 \mathrm{~mm}$ and $X_{i}=0$ otherwise, $i \in[1 ; 48]$.

As a further development, we seek the proposed new family of Rayleigh damping models to be confronted to other experimental evidence, criticized and improved. Albeit constructed on a stronger physical basis than commonly used damping models, there is yet no clear guarantee that this model remains consistent with the inelastic structural model it is coupled to, throughout inelastic time history analysis. Finally, such a proposition for a damping model should not eclipse the need for further improvement of the inelastic structural model, which would, for the case treated in this work, at least involve explicitly accounting for the inelastic response of the beam to column connections.

\section{Acknowledgements}

The authors thank Pr. André Filiatrault for providing the data from the shak- 

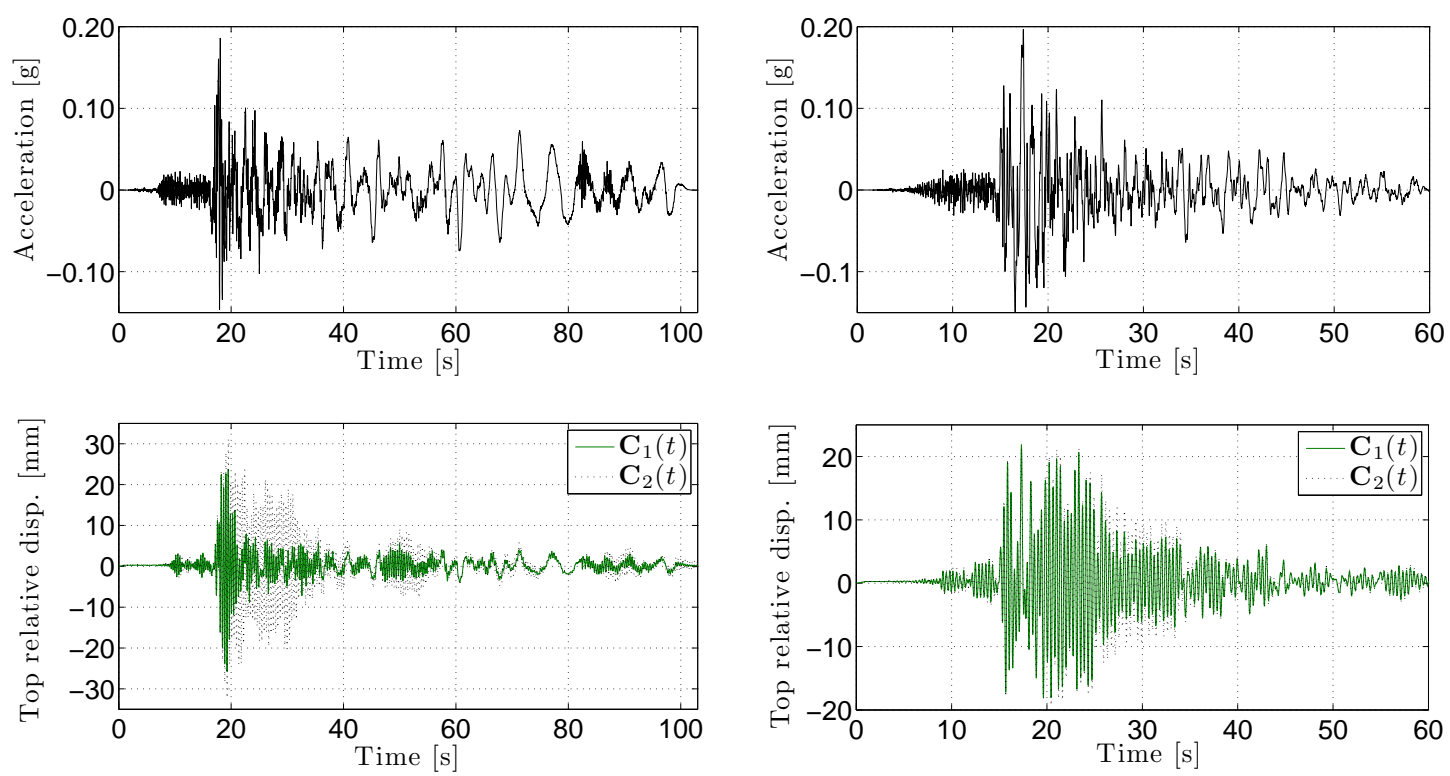

Figure 11: [left] Analysis where only phase 1 is activated for damping model $\mathbf{C}_{2}(t)$. [right] Analysis where three phases are accounted for in damping model $\mathbf{C}_{2}(t)$. [top] Ground motion time-history. [bottom] Top relative displacement time-history; Model $\mathbf{C}_{1}(t)$ with $\xi_{1}=\xi_{2}=3.3 \%$ all along the simulation; [bottom left] Model $\mathbf{C}_{2}(t)$ with $\xi_{1}=\xi_{2}=1 \%$ all along the simulation; [bottom right] Model $\mathbf{C}_{2}(t)$ with $\xi_{1}=\xi_{2}=1 \%$ for $0 \leq t \leq 15.4 s, \xi_{1}=\xi_{2}=4 \%$ for $15.4 s \leq t \leq 19 \mathrm{~s}$ and $\xi_{1}=\xi_{2}=2.5 \%$ for $19 s \leq t \leq 60 s$.

ing table tests used in this work. The first author benefited from partial funding from Électricité de France (EDF) within the research project "MARS" ("Modèles Avancés pour le Risque Sismique").

\section{References}

[1] Howard H.M. Hwang and Jun-Rong Huo. Generation of hazard-consistent fragility curves. Soil Dynamics and Earthquake Engineering, 13(5):345-354, 1994.

[2] F Jalayer and J L Beck. Effects of two alternative representations of ground-motion uncertainty on probabilistic seismic demand assessment of structures. Earthquake Engineering and Structural Dynamics, 37:61-79, 2008.

[3] B V Rosic, Hermann G Matthies, M Zikovic, and Adnan Ibrahimbegovic. Formulation and computational application of inelastic media with uncertain parameters. In 
E Oñate and D R J Owen, editors, Proceedings of the $10^{\text {th }}$ International Conference on Computational Plasticity (COMPLAS X), CIMNE, Barcelona, 2009.

[4] Cagdas Kafali and Mircea Grigoriu. Seismic fragility analysis: Application to simple linear and nonlinear systems. Earthquake Engineering and Structural Dynamics, 36:1885-1900, 2007.

[5] D.M. Seyedi, Pierre Gehl, J. Douglas, Luc Davenne, N. Mezher, and S. Ghavamian. Development of seismic fragility surfaces for reinforced concrete buildings by means of nonlinear time-history analysis. Earthquake Engineering and Structural Dynamics, 39:91-108, 2010.

[6] Esteban Patricio Sáez Robert, Fernando Lopez-Caballero, and Arezou ModaressiFarahmand-Razavi. Effect of the inelastic dynamic soil-structure interaction on the seismic vulnerability assessment. Structural Safety, 33(1):51-63, 2011.

[7] Vinita Saxena, George Deodatis, Masanobu Shinozuka, and Maria Q. Feng. Development of fragility curves for multi-span reinforced concrete bridges. In Proceedings of International Conference on Monte Carlo Simulation, Monte-Carlo, Monaco, 2000 .

[8] R. Popescu, J.H. Prevost, and George Deodatis. 3d effects in seismic liquefaction of stochastically variable soil deposits. Géotechnique, 55(1):21-31, 2005.

[9] Nikos D. Lagaros. Probabilistic fragility analysis: A tool for assessing design rules of rc buildings. Earthquake Engineering and Engineering vibration, 7(1):45-56, March 2008.

[10] Bruce R. Ellingwood. Earthquake risk assessment of building structures. Reliability Engineering \& System Safety, 74:251-262, 2001.

[11] Pierre Léger and Serge Dussault. Seismic-Energy Dissipation in MDOF Structures. ASCE Journal of Structural Engineering, 118(6):1251-1267, May 1992.

[12] J F Hall. Problems encountered from the use (or misuse) of Rayleigh damping. Earthquake Engineering and Structural Dynamics, 35:525-545, 2006.

[13] Finley A Charney. Unintended consequences of modeling damping in structures. Journal of Structural Engineering, 134(4):581-592, April 2008.

[14] Associate Committee on the National Building Code. National building code of canada. Technical report, National Research Council of Canada, Ottawa, Ontario, Canada, 1995.

[15] Design of concrete structures for buildings. Standard CAN-A23.3-94, Canadian Standards Association, Rexdale, Ontario, Canada, 1994. 
[16] André Filiatrault, Éric Lachapelle, and Patrick Lamontagne. Seismic performance of ductile and nominally ductile reinforced concrete moment resisting frames. i. experimental study. Canadian Journal of Civil Engineering, 25:331-341, 1998.

[17] Pierre Jehel, Luc Davenne, Adnan Ibrahimbegovic, and Pierre Léger. Towards robust viscoelastic-plastic-damage material model with different hardenings / softenings capable of representing salient phenomena in seismic loading applications. Computers and Concrete, 7(4):365-386, 2010.

[18] P. Germain, Q.S. Nguyen, and P. Suquet. Continuum thermodynamics. Journal of Applied Mechanics, 50:1010-1020, December 1983.

[19] G.A. Maugin. The Thermodynamics of Nonlinear Irreversible Behaviors - an Introduction. World Scientific. River Edge, Singapore, 1999.

[20] K. Garikipati and T.J.R. Hughes. A study of strain localization in a multiple scale framework - the one-dimensional problem. Computational Methods in Applied Mechanics and Engineering, 159:193-222, 1998.

[21] A. Ibrahimbegovic and D. Brancherie. Combined hardening and softening constitutive model of plasticity: precursor to shear slip line failure. Computational Mechanics, 31:89-100, 2003.

[22] J. Oliver and A.E. Huespe. Theoretical and computational issues in modelling material failure in strong discontinuity scenarios. Computer Methods in Applied Mechanics and Engineering, 193:2987-3014, 2004.

[23] R.L. Taylor. FEAP: A Finite Element Analysis Program, User manual and Programmer manual. University of California, Berkeley, California, 2005. Version 7.4.

[24] Applied Technology Council. Quantification of building seismic performance factors. Technical Report FEMA P695, Federal Emergency Management Agency, Washington, DC, June 2009.

[25] Applied Technology Council. Modeling and acceptance criteria for seismic design and analysis of tall buildings. Technical Report PEER 2010/111 or PEER/ATC72-1, Pacific Earthquake Engineering Research Center, Richmond (CA), October 2010.

[26] Helmut Krawinkler. Importance of good nonlinear analysis. The structural design of tall and special buildings, 15:515-531, 2006.

[27] Frédéric Ragueneau, Christian La Borderie, and Jacky Mazars. Damage model for concrete-like materials coupling cracking and friction, contribution towards structural damping: first uniaxial applications. Mechanics of cohesive-frictional materials, 5:607-625, 2000 . 
[28] René Tinawi, Pierre Léger, Martin Leclerc, and Giovanni Cipolla. Seismic safety of gravity dams: from shake table experiments to numerical analyses. ASCE Journal of Structural Engineering, 126(4):518-529, April 2000.

[29] Hieu Quang Luu, Iman Ghorbanirenani, Pierre Léger, and Robert Tremblay. Structural dynamics of slender ductile reinforced concrete shear walls. In EURODYN 2011, 2011.

[30] André Filiatrault, Éric Lachapelle, and Patrick Lamontagne. Seismic performance of ductile and nominally ductile reinforced concrete moment resisting frames. ii. analytical study. Canadian Journal of Civil Engineering, 25:342-351, 1998.

[31] CSI. Perform3D User's manual. Technical report, California, 2007.

[32] A Arias. Seismic design for nuclear power plants, chapter A measure of earthquake intensity, pages 438-483. MIT Press, Cambridge, MA, 1970.

[33] Julian J. Bommer and Ana Beatriz Acevedo. The use of real earthquake accelerograms as input to dynamic analysis. Journal of Earthquale Engineering, 8(S1):4391, 2004.

[34] Users manual for the PEER ground motion database web application. Technical report, Pacific Earthquake Engineering Research Center, November 2011.

[35] G E Baker and C Langston. Source parameters of the 1949 magnitude 7.1 South Puget Sound, Washington, eathquake as determinated from long-period body waves and strong ground motion. Bulletin of the Seismology Society of America, 77:1530$1557,1987$.

[36] Walter J Silva, Ivan G Wong, and Robert B Darragh. Assessing earthquake hazards and reducing risk in the Pacific Northwest, volume 2, U.S. geological survey professional paper 1560 Engineering characterization of earthquake strong motions in the Pacific Northwest, pages 313-324. United States Government Printing Office, Washington, 1998.

[37] Damaging capacity of Cascadia subduction earthquakes compared with Chilean subduction, Vancouver, B.C., Canada, August 1-6 2004. 13 ${ }^{\text {th }}$ World Conference on Earthqake Engineering.

[38] Katy R Wiest, Diane I Doser, Aaron A Velasco, and James Zollweg. Source investigation and comparison of the 1939, 1946, 1949 and 1965 earthquakes, cascadia subduction zone, western washington. Pure and Applied Geophysics, 164:1905-1919, 2007.

[39] Masanobu Shinozuka, M.Q. Feng, Jongheon Lee, and Toshihiko Naganuma. Statistical analysis of fragility curves. Journal of Engineering Mechanics, 126(12):12241231, December 2000. 
[40] Henri Poincaré. Calcul des Probabilités. Cours de la Faculté des Sciences de Paris - Cours de Physique mathématique. Gauthier-Villars, Paris, $2^{\text {nd }}$ edition, 1912. (In French).

[41] Pierre Léger, G. Kervégant, and Robert Tremblay. Incremental dynamic analysis of nonlinear structures: Selection of input ground motions. In Proceedings of the $9^{\text {th }}$ U.S. National and $10^{\text {th }}$ Canadian Conference on Earthquake Engineering, Toronto, Ontario, Canada, July 25-29 2010.

[42] Julian Bommer, Guido Magenes, Jonathan Hancock, and Paola Penazzo. The influence of strong-motion duration on the seismic response of masonry structures. Bulletin of Earthquake Engineering, 2:1-26, 2004. 10.1023/B:BEEE.0000038948.95616.bf.

[43] Y J Park, A H S Ang, and Y K Wen. Seismic damage analysis of reinforced concrete buildings. ASCE Journal of Structural Engineering, 111(4):740-757, 1985.

[44] C.A Castiglioni and Pucinotti R. Failure criteria and cumulative damage models for steel components under cyclic loading. Journal of Constructional Steel Research, 65:751-765, 2009. 